\title{
Analysis of Maternal and Infant Health Indicators in Kazakhstan: 2003-2018
}

\author{
Madina Abenova* (D), Ayan Myssayev² ${ }^{1}$, Lucy Kanya ${ }^{3}$ (i) , Daulet Aldyngurov ${ }^{4}$ (i) \\ ${ }^{1}$ Department of Public Health, NCJSC “Semey Medical University”, Semey, Kazakhstan; ${ }^{2}$ Department of Science and Human \\ Resources, Ministry of Health of the Republic of Kazakhstan, Nur-Sultan, Kazakhstan; ${ }^{3}$ Department of Health Policy, London \\ School of Economics and Political Science, London, England; ${ }^{4}$ Department of Science and Human Resources, Ministry of \\ Health of the Republic of Kazakhstan, Nur-Sultan, Kazakhstan
}

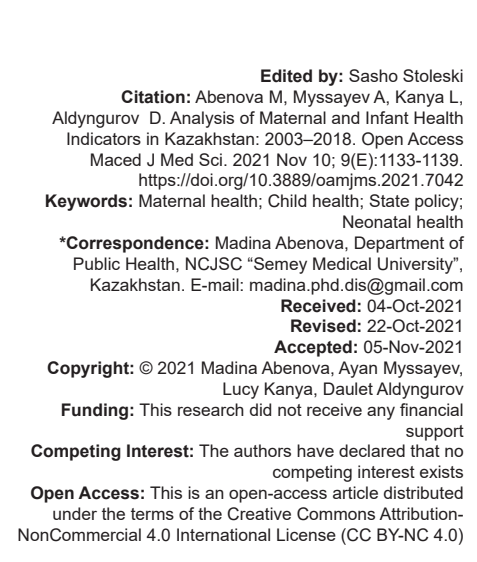

\section{Introduction}

The health status of women and children is the first and foremost priority for all countries in the world. In recent years, there has been a positive trend in demographic indicators around the world. Based on World Bank data, the world's total rate of natural increase was estimated at $2,287.85$ persons per thousand population (1.075\%) in 2020. Kazakhstan population is equivalent to $0.24 \%$ of the total world population, and the total rate of annual natural increase is $1.3 \%$ [1]. In the first decade of Kazakhstan's independence, the country's population was declining due to a significant loss of the population through migration. From 1992 to 2001, it decreased by over 1 million people, or $9.7 \%$. Since 2003, the population of Kazakhstan has been growing steadily, and this was projected as 18.7 million in 2021 [1]. Sustainable growth is mainly associated with the cessation of population migration and an increase in natural population growth [1], [2].

Accordingly, the protection of maternal and child health, an increase in the birth rate and a decrease in child and maternal mortality are the most important directions of state policy to improve the medical and demographic situation in the country. The need to improve the quality of medical services that meet the expectations and needs of the population has become a key area for the further development of the country's health care [2].

To achieve such positive demographic indicators, government programs play an important role. Over the 30 years of Independence, the Government has approved some state programs to improve various areas of the country's activities. Specialized health development programs were discussed and approved only at the beginning of 2009. The program "Salamatty Kazakhstan" was active for 5 years (2011-2015). It was 
then replaced by another state program "Densaulyk" which run from 2016 to 2019. The main goal of the state programs was to create conditions for ensuring the preservation and improvement of the life and health of mothers and children, prevention and reduction of morbidity among women and children, and improving the system of providing high-quality specialized medical care, improving the equipment of the material, and technical base of children's and maternity organizations in the country [3], [4]. The main target indicators of programs in the field of women's and children's health were to reduce maternal mortality by 3 times (from 22.7 to $9.7 / 100$ thousand live births) and infant mortality by 2 times (from 16.54 to $9.03 / 1000$ live births) from the level of 2010 .

The following main ways of achieving and measures were laid down in the state programs to achieve the target indicators:

- Strengthening the reproductive health of citizens and protecting the health of mothers and children by increasing the availability, quality, continuity of medical care;

- Improving screening programs for the diagnosis of congenital and hereditary diseases of the fetus and newborn;

- Introducing the WHO international standards and protocols for diagnosis and treatment in obstetrics, neonatology and pediatrics (including congenital malformations);

? Improving the professional level of medical workers of outpatient organizations, obstetric and children's hospitals; equipping children's and maternity organizations with modern medical equipment and medical products;

- $\quad$ Creating an effective system for providing family planning services, developing a national family planning manual and training medical personnel in social skills of family planning counseling;

- Improving the nutrition of children of different ages, women of reproductive age, pregnant and lactating women;

- $\quad$ Ensure the protection, promotion and support of breastfeeding and the timely introduction of adequate complementary foods for infants and young children [3], [4].

The effectiveness and results of the implementation of these programs on the health of women and children have not yet been fully evaluated. Thus, the main purpose of the article is to analyze the main indicators of maternal and neonatal health in Kazakhstan before and after the implementation of the state health development programs "Densaulyk" and "Salamatty Kazakhstan" in the context of two equal time periods: 2003-2010 and 2011-2018 and give suggestions to future state public health programs.

\section{Methods}

\section{Data collection}

We conducted a retrospective study using secondary data covering the periods before and after the implementation of the state programs. There are two other main databases of all medical statistics of Kazakhstan: Medinfo Database and www.stat.gov.kz (specifically, bala.stat.gov.kz and gender.stat.gov.kz). We retrieved data related to the status of maternal and child health in the entire country from 2003 to 2018 from those open source databases. We contacted and obtained some of the data missing from these databases from the Republican Center for Electronic Health (http://ezdrav.kz/). Relevant data for the period before 2003 were excluded as these were incomplete.

The Medinfo Company has an agreement with Ministry of Healthcare to develop, implement and maintain software products for medical organizations and health authorities. All indicators of interest are updated from 2003 until present. The information related to 16 regions of Kazakhstan is also available. Measures are categorized into 14 subgroups: Demography, mortality, morbidity, health service and human resources, medical organizations, hospital service, average length of stay, surgical operations in hospitals, outpatient care, maternal and child health service, diagnostic and other procedures, and hospital mortality.

Data on the total number of pregnant and parturient women, total number of women of reproductive age (15-49 years), and number of children under 1 year was given by Republican Center for Electronic Health.

This research was approved by the Ethical committee of Semey Medical University (Semey, Kazakhstan(protocol 1 dated 18 February 2021). The entire dataset used for analysis was collected from official sources and was extracted from "Medinform" database, www.stat.gov.kz and Republican Center for Electronic Health, which are official open source databases and the structural subdivision of Ministry of Health. The data on population numbers were obtained from official websites of the World bank and the Statistical yearbooks issued by the Agency of Statistics, Kazakhstan (https://www.worldbank.org/en/country/ kazakhstan/overview and http://www.rcrz.kz/index.php/ ru/statistika-zdravookhraneniya-2).

\section{Statistical analysis}

All indicators presented on the Medinfo database, www.stat.gov.kz and the Republican Center for Electronic Health were grouped into two categories: Maternal and infant related indicators (Table 1). 
Table 1: Basic maternal health indicators in the Republic of Kazakhstan: 2003-2018

\begin{tabular}{|c|c|c|c|c|c|}
\hline & $\begin{array}{l}\text { Women of reproductive } \\
\text { age ( } 15-49 \text { years) (average } \\
\text { annual number } 0.000)\end{array}$ & $\begin{array}{l}\text { Pregnant } \\
\text { women (number) }\end{array}$ & $\begin{array}{l}\text { Women with pregnancy up to } \\
12 \text { weeks (as a \% of total pregnant } \\
\text { women) }\end{array}$ & $\begin{array}{l}\text { Maternal mortality } \\
\text { rate (number) }\end{array}$ & $\begin{array}{l}\text { Contraception } \\
\text { coverage (\%) }\end{array}$ \\
\hline $\begin{array}{l}\text { Mean } \\
2003-2010 \\
2011-2018\end{array}$ & $\begin{array}{l}4388.9 \\
4567.2\end{array}$ & $\begin{array}{l}324184 \\
389393\end{array}$ & $\begin{array}{l}70.4 \\
77.3\end{array}$ & $\begin{array}{l}117 \text { (939 total) } \\
52 \text { (422 total) }\end{array}$ & 14.8 \\
\hline Trends & $4.06 \%$ & $20.1 \%$ & $6.9 \%$ & $122.5 \%$ & $12.8 \%$ \\
\hline
\end{tabular}

The Maternal health indicators include: Number of women of reproductive age (15-49 years) (average annual number), pregnant women (number), women with pregnancy up to 12 weeks (as a \% of total number of pregnant women), maternal mortality rate (number), contraception coverage (\%), distribution of deliveries, abortions, rate of Caeserean-sections (C-section) and complications from pregnancy and childbirth (average number), number of obstetrician-gynecologists per 1000 live and still births, number of hospital beds for pregnant women, women in labor and parturient women per 1000 live and still births, and the average number of all hospitals that provide maternity care in Kazakhstan.

Infants health indicators include: Total number of live births per 1000 population, infant mortality rate (up to 1 year) per 1000 live births, perinatal mortality rate per 1000 live births, life expectancy at birth (years), morbidity of infants under 1 year/1000 children during the $1^{\text {st }}$ year of life, children breastfed up to 6 months of age (\%), total number of full- and pre-term born babies (average number), leading causes of morbidity of infants under 1 year/1000 children during the $1^{\text {st }}$ year of life, number of hospitals with children's outpatient departments and offices (number), provision with pediatricians (including neonatologists) per 1000 children of the $1^{\text {st }}$ year of life, and provision of children's hospital beds per 1000 children of the $1^{\text {st }}$ year of life.

To compare maternal and infant indicators before and after implementation of state programs "Salamatty Kazakhstan" and "Densaulyk" we used the average values for all indicators. All calculations were performed on the basis of the approved methodology for calculating indicators in Kazakhstan with SPSS (Statistical Package for the Social Sciences) software, version 20.0 for Windows.

\section{Results}

\section{Maternal health indicators}

The average annual number of women of reproductive age (15-49) from 2003 to 2010 was $4,388,963$, and from 2011 to $20184,567,288$. This represents $28.36 \%$ and $26.17 \%$ of the average annual population of the country over these years, respectively. The number of pregnant women admitted under the supervision of antenatal clinics averaged
324,184 (2003-2010) and 389,919 (2011-2018). This is $7.38 \%$ and $8.53 \%$ of the average annual number of women of reproductive age (15-49) and $2.09 \%$ and $2.23 \%$ of the total population, respectively.

Table 1 summarises the basic maternal health indicators in Kazakhstan over these 2 time periods covering 16 years. All except one indicator has increased but the direction is positive. Notably, the maternal mortality rate declined more than twofold.

Figure 1 illustrates the trends in the number of deliveries, abortions, rate of C-sections and complications from pregnancy and childbirth in Kazakhstan from 2003 to 2018.

While the number of deliveries increased following the implementation of state programs, there was a decline in the number of complications from pregnancy and childbirth and total number of abortions. More than $16 \%$ of births occurring in the 8 year period after the implementation of the state programs (2011-2018) were by C-sections. This represents a twofold increase from the 2003 to 2010 period.

Table 2 shows provision of obstetrics and gynecology services in Kazakhstan from 2003 to 2018. During this period, the number of obstetriciangynecologists per 1000 live and still births decreased from 11.6 to 10 . The number of hospital beds for pregnant women, women in labor, and parturient women also decreased from 31.6 to 22.9 (per 1000 live and still births) between 2011 and 2018. The average number of all hospitals that provide maternity care in Kazakhstan ranged from 844.7 to 887.6 , which is $5.07 \%$ more than in 2003 to 2010 .

According to annual statistical yearbooks issued by the Agency of Statistics [5], [6], [7], [8], [9], [10], [11], [12], [13], [14], [15], [16], [17], [18], [19], [20], [21], there were differences in the mean number of hospitals that provide maternity care in the 16 regions of Kazakhstan between 2003 and 2018 (Figure 2). There were notable increases in numbers of all hospitals that provide maternity care in regions such as West Kazakhstan (12.3), Atyrau (7), Mangystau (21), Aktobe (5), Kostanay (1.8), Akmola (12.5), Almaty (52.7), Astana city (14.8), and Almaty city (28.3) during the period 2011-2018. However, a decline was recorded in regions such as Kyzylorda (10), South Kazakhstan (42.8), Zhambyl (42.3), Karaganda (7.9), North Kazakhstan (2), Pavlodar (28.8), and East Kazakhstan (8.4) during the same period. 


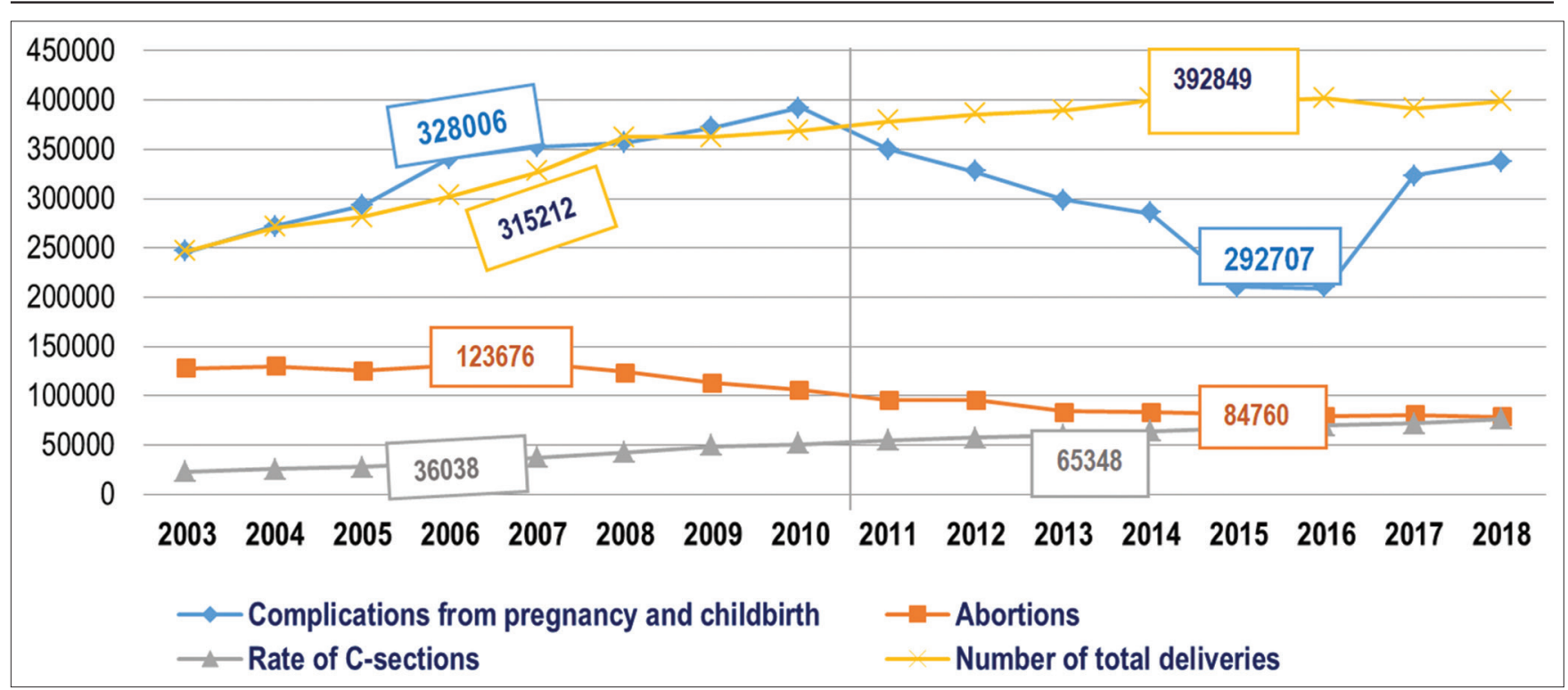

Figure 1: Distribution of deliveries, abortions, rate of C-sections and complications from pregnancy and childbirth in Kazakhstan from 2003 to 2018 (mean)

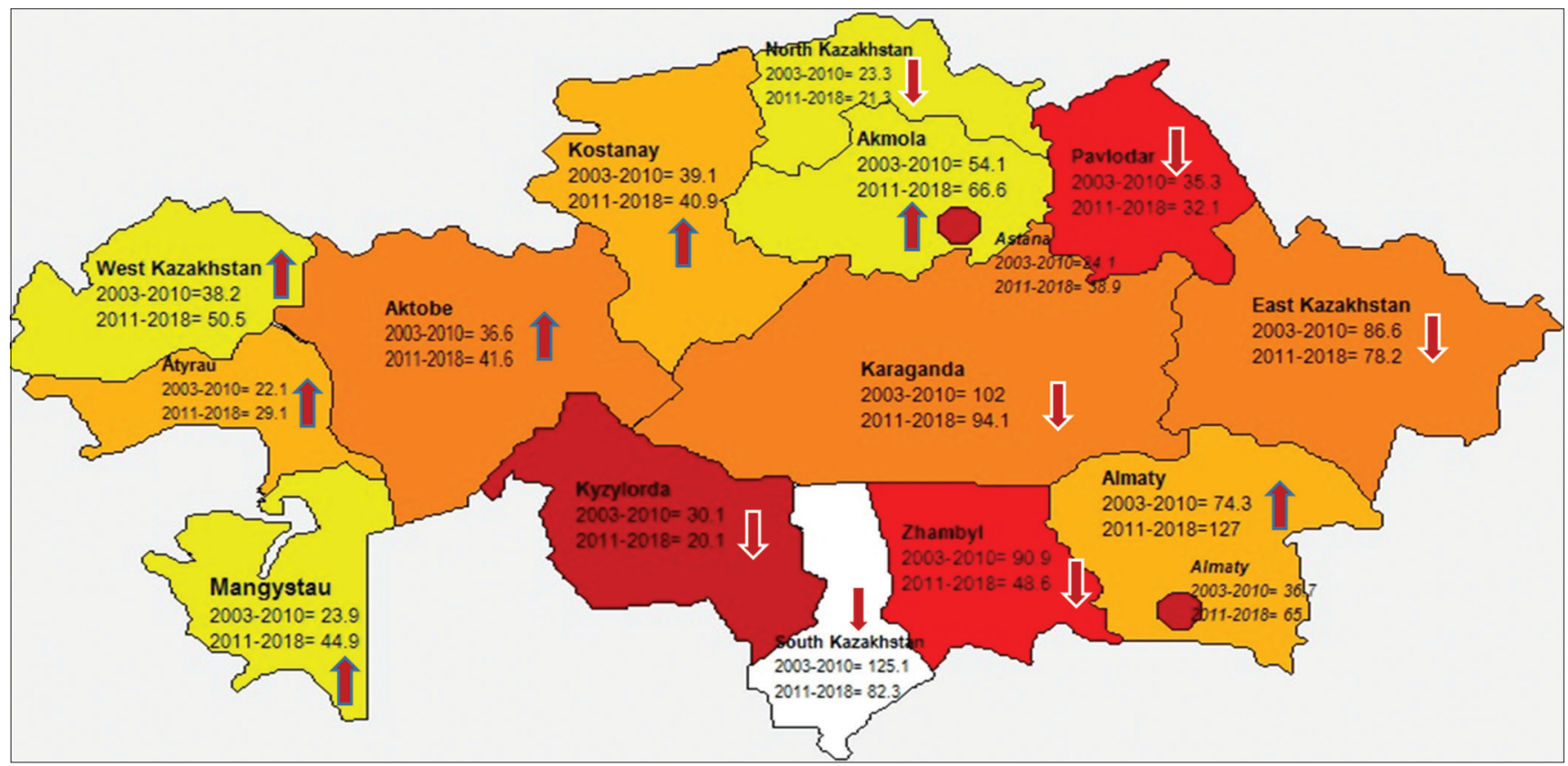

Figure 2: Numbers of all hospitals that provide maternity care in Kazakhstan (mean): 2003-2018

\section{Infant health indicators}

Table 3 presents data about basic infant health indicators in Kazakhstan from 2003 to 2018. Data were analyzed for the 2 equal time periods: 2003-2010 and 2011-2018. The analysis highlights a positive trend in the number of live births, infant and perinatal mortality rate,

Table 2: Provision of obstetrics and gynecology services in the Republic of Kazakhstan: 2003-2018

\begin{tabular}{llll}
\hline Indicators (per 1000 live and still births) & $2003-2010$ & $2011-2018$ & Trends \\
\hline Number of Obstetrician-gynecologists & 11.6 & 10 & $16 \%$ \\
$\begin{array}{l}\text { Number of hospital beds for pregnant women, } \\
\text { women in labor and parturient women }\end{array}$ & 31.6 & 22.9 & $37.9 \%$ \\
$\begin{array}{l}\text { Number of all hospitals that provide maternity care } \\
\text { in Kazakhstan (average number) }\end{array}$ & 844.7 & 887.6 & $5.07 \%$ \\
\hline
\end{tabular}

life expectancy at birth, and morbidity of infants under year during the periods 2011-2018 than 2003-2010. The total number of live births increased by $10.9 \%$ (per 1000 population), infant mortality rate (per 1000 live births) decreased by $54.8 \%$, perinatal mortality rate dropped by $20.3 \%$ (per 1000 live births), life expectancy at birth had an upward trend for almost 5 years ( 5 years for male and 3 years for female), infant morbidity increased by $41.3 \%$ (1000 children of the $1^{\text {st }}$ year of life) and the percentage of children breastfed up to 6 months of age increased from 74.9 to 78.9 .

As illustrated in Figure 3 , the total number of full- and pre-term born babies has increased by an average of $25.4 \%$ and $28.1 \%$, respectively, following 
Table 3: Basic infant health indicators in the Republic of Kazakhstan: 2003-2018

\begin{tabular}{|c|c|c|c|c|c|c|}
\hline Years & $\begin{array}{l}\text { Total number of live } \\
\text { births (per } 1000 \\
\text { population) }\end{array}$ & $\begin{array}{l}\text { Infant mortality rate (up } \\
\text { to } 1 \text { year/1000 live } \\
\text { births) }\end{array}$ & $\begin{array}{l}\text { Perinatal mortality } \\
\text { rate (per } 1000 \text { live } \\
\text { births) }\end{array}$ & $\begin{array}{l}\text { Life expectancy at } \\
\text { birth (years) }\end{array}$ & $\begin{array}{l}\text { Morbidity of infants under } \\
1 \text { year (absolute and proportion) }\end{array}$ & $\begin{array}{l}\text { Children breastfed } \\
\text { up to } 6 \text { months of } \\
\text { age }(\%)\end{array}$ \\
\hline 2003-2010 (mean) & 20.25 & 16.12 & 15.55 & $\begin{array}{l}66,6 \\
(61.36 \text { male, } \\
72.1 \text { female) }\end{array}$ & $\begin{array}{l}5,044,219 \\
\text { (absolute numbers) } \\
2284.1 \\
\text { (per } 1000 \text { children of the } 1^{\text {st }} \\
\text { year of life) }\end{array}$ & 74.9 \\
\hline 2011-2018 (mean) & ${ }_{22.46} \uparrow$ & $10.41 \downarrow$ & $12.92 \downarrow$ & $\begin{array}{l}71.3 \\
(66.8 \text { male, } \\
75.7 \text { female })\end{array}$ & $\begin{array}{l}4,539,172 \\
\text { (absolute numbers) } \\
1615.6 \\
\text { (per } 1000 \text { children of the } 1^{\text {st }} \\
\text { year of life) }\end{array}$ & 78.9 \\
\hline
\end{tabular}

the implementation of the state health development programs "Densaulyk" and "Salamatty Kazakhstan."

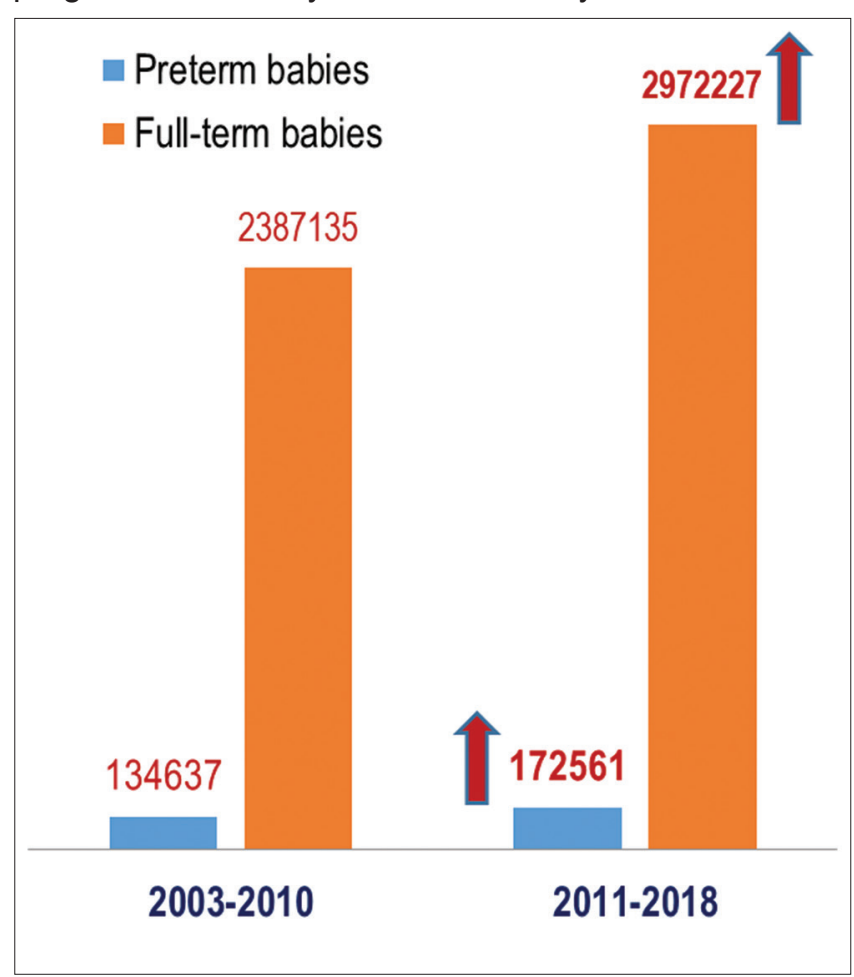

Figure 3: Total number of full-term and preterm born babies (live births)

The most common disease among children during this period was respiratory diseases, which was almost twofold higher in 2003-2010 than in 2011-2018 (Figure 4). In general, most of the diseases showed a decrease over the entire time period, exept nervous system diseases and congenital anomalies. There was a negligible increase in these two: From 95.8 to 141.6 per 1000 children within the $1^{\text {st }}$ year of life and 35.7 to 46.9 per 1000 children within the $1^{\text {st }}$ year of life). This represents a $47.8 \%$ and $31.3 \%$ increase in nervous system diseases and congenital anomalies, respectively, in the 2011-2018 period compared to 2003-2010.

Table 4 demonstrates provision of pediatric services in Kazakhstan during the periods 2003-2010 and 2011-2018. The number of hospitals with children's outpatient departments and offices was almost at the same level during the 16 years. Notably, only one department or office was added. The average provision by pediatricians (including neonatologists) in

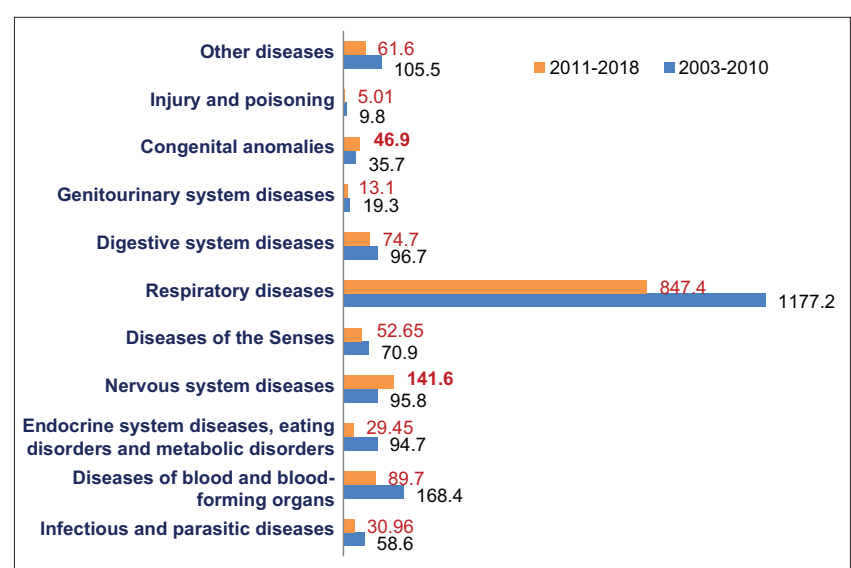

Figure 4: Leading causes of morbidity of infants under 1 year (mean)

Kazakhstan dropped from 1.47 to 1.15 per 1000 children (0-14 years) during the time. In addition, the number of children's hospital beds per 1000 children (0-14 years) decreased from 5.01 to 4.01 from 2011 to 2018.

\begin{tabular}{|c|c|c|c|}
\hline & $\begin{array}{l}2003- \\
2010 \text { (mean) }\end{array}$ & $\begin{array}{l}2011- \\
2018 \text { (mean) }\end{array}$ & Trends \\
\hline $\begin{array}{l}\text { The number of hospitals with children's } \\
\text { outpatient departments and offices (number) }\end{array}$ & 1174 & 1175 & $\uparrow$ \\
\hline $\begin{array}{l}\text { Provision with pediatricians (including } \\
\text { neonatologists) per } 1000 \\
\text { children ( } 0-14 \text { years) }\end{array}$ & 1.47 & 1.15 & $\downarrow$ \\
\hline $\begin{array}{l}\text { Provision of children's hospital beds for } 1000 \\
\text { children } \\
\text { (0-14 years) }\end{array}$ & 5.01 & 4.01 & $\downarrow$ \\
\hline
\end{tabular}

\section{Discussion}

In the $1^{\text {st }}$ years of independence, Kazakhstan experienced significantly negative trends in the demographic situation: A decline in natural population growth, an increase in mortality and morbidity rates, and low birth rates [22]. The main reason for this trend is associated with the migration of some representatives of ethnic groups to their historical homeland and a drop in the birth rate. Since 2003, the population in the country has increased. Despite the positive changes in the demographic situation since 2003, the challenges with poor health status of women and children remain important [22]. 
A high level of infertility (up to $16 \%$ of all marriages), a wide prevalence of sexually transmitted infections, a high level of abortions, a high level of registered cases of artificial termination, an increase in the frequency of childbirth among adolescent girls (31.1/1000 population), maternal mortality due to obstetric bleeding, gestosis and extragenital pathologies (2005-40.5, 2009-36.9/100 thousand live births.), the insufficient level of early diagnosis (screening of pregnant women for the detection of congenital pathologies), the mortality of children under 1 year from respiratory diseases, pneumonia and infectious diseases, the lack of any data on the psychological nosologies of women after childbirth were the main reason for the development of state programs which aimed to reduce these indicators [3], [4].

Thus, the main key indicators for the state programs "Salamatty Kazakhstan" and "Densaulyk" were more related to maternal and child health by achieving coherence of the whole society efforts in matters of health protection [3], [4].

Based on the results of the analysis and comparison of all indicators, two main trends can be identified. This is an increase in the incidence of cesarean sections during delivery, and a significant increase in cases of nervous system diseases and congenital anomalies among infants under 1 year. When considering the reasons and strategies for each of the listed indicators, it can be seen that an increase in the incidence of caesarean sections is observed around the world and Kazakhstan is no exception. It is therefore difficult to identify a relationshiop with the implementation of the program. However, in their study, Tadevosyan et al. [23] highlight in their work that financial incentives for doctors, women's requests, and lack of regulatory requirements can all contribute to an increase in elective caesarean section. In a different study, Miseljic et al., [24] highlighted an increase in unverified indications for cesarean sections in women in Bosnia and Herzegovina. In the government program, we did not find any evidence pointing to the need to focus on reducing the incidence of caesarean sections. Although the consequences of surgical placement during delivery are very dangerous for the health of the woman and the newborn, the WHO indicates outlines some short-term and longterm risks of post-cesarean section on the health of women, children, and future pregnancies. These include problems related to anesthesia, post-operative infection, high hemorrhage and thrombosys [25]. Findings from our analysis suggest that future state programs need to take into account these WHO recommendations and develop their own manual and educational program for women, adapting this to the realities of the country.

Congenital anomalies are still the leading cause of infant mortality and morbidity in Kazakhstan. However, compared to Russia, Ukraine, and Belarus - countries with similar socioeconomic conditions-the infant mortality rate in Kazakhstan is much higher [2].

An increase in the number of cases can have a twofold meaning. This may indicate an improvement in screening measures for pregnant women or an insufficient effectiveness and monitoring of the measures taken. Both in the first and second case, it is necessary to constantly monitor the measures taken. It is necessary to focus on family planning and education of married couples about the healthy lifestyle and possible risks and on neonatal care of newborns. The WHO strategic plan for 2016-2030 [26] points to evidence-based health interventions for women's, children's, and adolescents' health. The importance of timely accommodation in the prenatal, antenatal and postnatal periods for the health of women and children is emphasized. Analyzing statistical data collections and the official website of the electronic health site of the Republic of Kazakhstan, we noticed that there is also a lack of data on the psychological health of women during pregnancy and post partum. Although in the international strategic plan, the identification of postpartum depression has an important place and significance. The results of the state program "Salamatty Kazakhstan" 2016-2019 allowed the introduction of a universal and progressive model of patronage of services for pregnant women and young children. Taking this into account, it is necessary to analyze the demographic situation after the modernization of the patronage service. The updated approaches of the patronage service will allow assessing the social risks that threaten the health and well-being of the child, the attitude of the parents toward the child and attachment, maternal or paternal depression, and the presence of strained relationships in the family, which ultimately determine the health, vitality, development and well-being of the child. These indicators should also be reflected in information databases and statistical compilations to describe the whole picture of maternal and infant health.

\section{Limitations}

This study had several limitations. The databases lacked data for the last 2 years, which hindered limited the illustration of the situation most recently. However, available data were sufficient for a comparative analysis of the period before and after the implementation of the state programs, allowing for a consideration of the impact. There were no data on the statistics of the nursing service and the psychological health of women during pregnancy and postpartum. 


\section{Conclusion}

The purpose of the article was to assess the indicators of maternal and infant health before and after the implementation of the state programs "Densaulyk" and "Salamatty Kazakhstan." This assessment will help draw attention to indicators of maternal and child health that need to be improved in the development of future public health programs. Two equal time periods allowed us to avoid systematic errors in comparison. We used average values in all indicators.

Health indicators related to mother, pregnancy and children under 1 year old showed favorable trends following the implementation of the state programs "Densaulyk" and "Salamatty Kazakhstan." However, the high rate of $\mathrm{C}$-section and congenital anomalies, and the lack of data on psychological health indicators also requires changes in prevention and education systems regarding to the WHO recommendations for non-clinical interventions. This includes the global strategy for women's, children's, and adolescents' health (2016-2030) taking into account the national characteristics and realities of the country. Further research is also needed to inform interventions to address the psychological health of women at the antenatal and postnatal levels for a wholistic improvement of women's health status.

\section{References}

1. Poliacof C, Bugay V. Rate of Natural Increase; 2021. Available from: https://www.knoema.com/atlas/topics/demographics/ population/rate-of-natural-increase; https://www.knoema.com [Last accessed on $2021 \mathrm{Mar} 20$ ].

2. UNFPA in Kazakhstan. Report "Analysis of the Population Situation in the Republic of Kazakhstan; 2019.

3. Decree of the President of the Republic of Kazakhstan dated January 15, 2016 No. 176. On Approval of the State Program for the Development of Health Care of the Republic of Kazakhstan "Densaulyk" for 2016-2019; 2015.

4. Decree of the President of the Republic of Kazakhstan dated November 29, 2010 No. 1113. On approval of the State Program for the Development of Health Care of the Republic of Kazakhstan "Salamatty Kazakhstan" for 2011-2015; 2010.

5. Ministry of Health of Kazakhstan. Health of the Population of the Republic of Kazakhstan and the Activities of Health Care Organizations in 2003 (Statistical Collection); 2003. p. 152-80.

6. Ministry of Health of Kazakhstan. Health of the Population of the Republic of Kazakhstan and the Activities of Health Care Organizations in 2004 (Statistical Collection); 2004. p. 173-88.

7. Ministry of Health of Kazakhstan. Health of the Population of the Republic of Kazakhstan and the Activities of Health Care Organizations in 2005 (Statistical Collection); 2005. p. 170-85.

8. Ministry of Health of Kazakhstan. Health of the Population of the Republic of Kazakhstan and the Activities of Health Care Organizations in 2006 (Statistical Collection); 2006. p. 225-44.

9. Ministry of Health of Kazakhstan. Health of the Population of the Republic of Kazakhstan and the Activities of Health Care Organizations in 2007 (Statistical Collection); 2007. p. 177-93.

10. Ministry of Health of Kazakhstan. Health of the Population of the Republic of Kazakhstan and the Activities of health Care Organizations in 2008 (Statistical Collection); 2008. p. 225-44.

11. Ministry of Health of Kazakhstan. Health of the Population of the Republic of Kazakhstan and the Activities of Health Care Organizations in 2009 (Statistical Collection); 2009. p. 177-93.

12. Ministry of Health of Kazakhstan. Health of the Population of the Republic of Kazakhstan and the Activities of Health Care Organizations in 2010 (Statistical Collection); 2010. p. 227-41.

13. Ministry of Health of Kazakhstan. Health of the Population of the Republic of Kazakhstan and the Activities of Health Care Organizations in 2011 (Statistical Collection); 2011. p. 227-41.

14. Ministry of Health of Kazakhstan. Health of the Population of the Republic of Kazakhstan and the Activities of Health Care Organizations in 2013 (Statistical Collection); 2013. p. 261-76.

15. Ministry of Health of Kazakhstan. Health of the Population of the Republic of Kazakhstan and the Activities of Health Care Organizations in 2014 (Statistical Collection); 2014. p. 261-76.

16. Ministry of Health of Kazakhstan. Health of the Population of the Republic of Kazakhstan and the Activities of Health Care Organizations in 2015 (Statistical Collection); 2015. p. 263-77.

17. Ministry of Health of Kazakhstan. Health of the Population of the Republic of Kazakhstan and the Activities of Health Care Organizations in 2016 (Statistical Collection); 2016. p. 263-77.

18. Ministry of Health of Kazakhstan. Health of the Population of the Republic of Kazakhstan and the Activities of Health Care Organizations in 2017 (Statistical Collection); 2017. p. 261-75.

19. Ministry of Health of Kazakhstan. Health of the Population of the Republic of Kazakhstan and the Activities of Health Care Organizations in 2018 (Statistical Collection); 2018. p. 152-80.

20. Company LLP "Medinform", Medical Statistics; 2021. Available from: http://www.medinfo.kz [Last accessed on 2021 Mar 25].

21. Bureau for National Statistics. Demographic Characteristics 2021. Available from: https://www.bala.stat.gov.kz/ category/demograficheskie-harakteristiki [Last accessed on 2021 Mar 25].

22. The World Bank. Kazakhstan Overview-World Bank Group 2021. Available from: https://www.data.worldbank.org/ indicator/sp.pop.grow?locations $=\mathrm{kz}$ [Last accessed on 2021 Aug 27].

23. Tadevosyan M, Ghazaryan A, Harutyunyan A, Petrosyan V, Atherly A, Hekimian K. Factors contributing to rapidly increasing rates of cesarean section in Armenia: A partially mixed concurrent quantitative-qualitative equal status study. BMC Pregnancy Childbirth. 2019;19(1):2. https://doi.org/10.1186/ s12884-018-2158-6 PMid:30606147

24. Miseljic N, Basic E, Miseljic S. Causes of an increased rate of caesarean section. Mater Sociomed. 2018;30(4):287-9. https:// doi.org/10.5455/msm.2018.30.287-289 PMid:30936794

25. World Health Organization. WHO Recommendations NonClinical Interventions to Reduce Unnecessary Caesarean Sections. Geneva: World Health Organization; 2018. p. 3-82.

26. World Health Organization. WHO Recommendations NonClinical Interventions to Reduce Unnecessary Caesarean Sections. Geneva: World Health Organization; 2018. p. 3-82. 